\title{
DOIS PAIISES, O MESMO DILEMA? REFLEXÕES SOBRE A DEMOCRACIA E O RACISMO NOS ESTADOS UNIDOS E NO BRASIL
}

Two countries, the same dilemma? Reflections on democracy and racism in the United States and Brazil

¿Dos países, el mismo dilema? Reflexiones sobre la democracia y el racismo en Estados Unidos y Brasil

GUSTAVO MESQUITA ${ }^{\mathrm{I}}$

DOI: http://dx.doi.org/10.1590/\$2178-14942019000200006

\footnotetext{
' Fundação Getulio Vargas (FGV), Rio de Janeiro - RJ, Brasil.

* Pós-doutorando no Centro de Pesquisa e Documentação de História Contemporânea do Brasil da Fundação Getulio Vargas e doutor em História Social pela Universidade de São Paulo, com estágio na Vanderbilt University, Nashville, Estados Unidos. (gustavormesquita@gmail.com) ORCID iD: https://orcid.org/0000-0002-6460-495X
}

Artigo recebido em 10 de março de 2019 e aceito para publicação em 26 de junho de 2019. 


\title{
RESUMO
}

Roger Bastide e Florestan Fernandes atuavam em pesquisas sobre relações raciais financiadas por organizações internacionais quando, na década de 1960, os Estados Unidos criaram ações afirmativas para responder à desigualdade racial. As conclusões dos sociólogos estimularam discussões acerca do mesmo problema no Brasil. Entendeu-se naquela época que também temos um dilema, ou seja, uma democracia fracionada, excludente da população negra. Discuto neste artigo a formação do pensamento sociológico de Bastide e Fernandes à luz de teses norte-americanas de relações raciais, assim como o impacto desse pensamento no debate sobre racismo brasileiro.

PALAVRAS-CHAVE: Relações raciais; Sociedade de classes; Desigualdade; Direitos humanos.

\begin{abstract}
Roger Bastide and Florestan Fernandes carried out researches on race relations sponsored by international organizations when, in the 1960s, the United States created affirmative actions to respond to its racial inequality. Conclusions from the sociologists enhanced discussions about the same issue in Brazil. The time has come for the understanding that our democracy excludes the Negro population. It is analyzed in this article the formation of Bastide and Fernandes' sociological thought under American thesis of race relations, as well as the impact of this thought over the debate on Brazilian racism.
\end{abstract}

KEYWORDS: Race Relations; Class Society; Inequality; Human Rights.

\section{RESUMEN}

Roger Bastide y Florestan Fernandes actuaban en investigaciones sobre relaciones raciales financiadas por organizaciones internacionales cuando, en los años 1960, los Estados Unidos creó acciones afirmativas para responder a su desigualdad racial. Las conclusiones de los sociólogos estimularon discusiones sobre el mismo problema en Brasil. Se entendió en aquella época que también teníamos un dilema, o sea, una democracia fraccionada, excluyente de la población negra. Discuto en este artículo la formación del pensamiento sociológico de Bastide y Fernandes a la luz de tesis estadounidenses de relaciones raciales, así como el impacto de este pensamiento en el debate sobre racismo brasileño.

PALAbRAS ClAVE: Relaciones raciales; Sociedad de clases; Derechos humanos. 
E m 1958, Florestan Fernandes publicou na revista Anhembi um balanço dos estudos raciais financiados pela Organização das Nações Unidas para a Educação, a Ciência e a Cultura (Unesco). ${ }^{1}$ Tendo como amarra os avanços que a inserção do negro atingira no mercado de trabalho das democracias ocidentais, os exames vinculados à organização internacional eram realizados por cientistas sociais oriundos não só dos Estados Unidos e da Europa, mas do Brasil e de outros países igualmente chamados, nessa época, de subdesenvolvidos.

Um periódico científico, editado pela mesma organização numa espécie de rede transnacional, difundia mundialmente as mais novas pesquisas de relações raciais. Trata-se do International Social Science Bulletin, que era tão importante quanto a revista The Unesco Courier, também comprometida com a questão racial, para o esforço de divulgação das políticas que essa organização desenvolvia em busca do entendimento global e da eliminação do racismo nas democracias modernas.

As três revistas estavam comprometidas com a formação de uma interpretação da questão racial tida como capaz de apontar soluções para os problemas criados pelo fenômeno. Em outras palavras, buscavam uma interpretação do tema do negro colocado à democracia moderna. 0 vínculo entre democracia e racismo era pensado de forma abrangente, pois era pertinente a qualquer país em que as relações raciais, carregadas de barreiras do preconceito, representavam um entrave ao desenvolvimento da sociedade de classes e à subsequente inserção do negro nesse sistema social.

Os artigos publicados nas revistas complementavam e divulgavam as pesquisas raciais iniciadas pouco tempo antes em vários países, tendo o Brasil e sua intensa miscigenação como ponto de referência. A urgência dessa nova produção científica em meio ao pós-Segunda Guerra Mundial, viabilizada pelos programas da Unesco para o desenvolvimento das ciências sociais em escala global, era alimentada pela consciência dos horrores cometidos durante 0 período bélico, incluindo o holocausto, o racismo e a xenofobia (MAIO, 1997).²

Fernandes apresentou em Anhembi a contribuição dos sociólogos interacionistas, formados na Universidade de Chicago, para o dossiê do International Social Science Bulletin sobre a situação do negro nos Estados Unidos. Os artigos de Herbert Blumer, Franklin Frazier, St. Clair Drake e H. J. Walker foram mencionados. 0 mais importante, porém, reside na ênfase dada pelo sociólogo paulista ao artigo de Roger Bastide, publicado no mesmo número da revista internacional.

Bastide participou do número com a introdução a respeito dos Estados Unidos e um artigo especial preparado para esse dossiê. Mas o artigo não se refere à sociedade norteamericana de maneira isolada. Ao comparar Estados Unidos e Brasil, Bastide abordou o lugar 
do negro na hierarquia social das duas sociedades. A conclusão do sociólogo, como veremos adiante, veio acompanhada de uma crítica ao racismo brasileiro que indicava caminhos possíveis para o reverso da moeda: o antirracismo, nascido, segundo ele, junto às aceleradas mudanças urbano-industriais.

Fernandes valorizou a contribuição de Bastide, como seu texto mostra, porque o entendimento do problema negro norte-americano foi incorporado nas reflexões do sociólogo francês. Para esses sociólogos, o entendimento externo era significativo para a decifração do problema negro brasileiro. As relações entre Brasil e Estados Unidos começariam no tratamento correto do conceito de raça pelos pesquisadores de ambos os países. Notemos o que Bastide dissera sobre isso: "A característica do presente [em relação à raça] é a progressiva transição da dinâmica das relações raciais para a das relações humanas; cor agora é vista apenas como variável numa situação geral, afetada por muitos outros fatores" (1957: 423).

No momento em que tal definição de relações raciais foi feita, era comum, para a compreensão da situação geral, o conceito de cor vir acompanhado de seu par: a ascensão social. Nos anos 1950, as noções de cor e ascensão social formaram um par cujo poder de explicação, à luz da psicologia social e da sociologia, se tornou diretriz endossada pela Unesco para os estudos de relações raciais em curso naquele momento (Guimarães, 2009).

Os grupos de cor passaram a ser o mais importante dos fatores operativos da análise histórico-sociológica das relações raciais no decurso da formação nacional. São o conceito de raça com o qual Bastide e Fernandes fizeram suas pesquisas sob subvenção da Unesco. No artigo em Anhembi, três anos depois das Relações raciais entre negros e brancos em São Paulo, o sociólogo paulista fez considerações sobre cor que combinam com as do francês, tecidas no International Social Science Bulletin. Ele argumentou que a importância da cor - das cores preta e parda, que compõem o grupo negro - reside em seu grande peso na análise de uma situação social mais ampla. Esse conceito de raça era aplicado nas pesquisas da maioria dos cientistas sociais, além dos norte-americanos, brasileiros:

A maioria dos especialistas tende a interessar-se pelo negro na medida em que ele pode ser encarado como um dos fatores operativos em uma situação social mais ampla e complexa. Só alguns cientistas negros se especializaram no estudo do negro propriamente dito. (Fernandes, 1958: 105)

Ao retomar as teses das Relações raciais entre negros e brancos em São Paulo, Bastide, em 1957, e Fernandes, em 1958, desenvolveram argumentos parecidos, ambos dando a entender que a cor do negro interfere numa situação geral. Afinal, que situação é essa? A parceria internacional das revistas nos ajuda a entendê-la. No balanço feito pelo sociólogo paulista 
sobre os Estados Unidos, o sistema social igualitário - sistema de organização da sociedade em igualdade de condições num regime democrático que garantisse tratamento igual às classes sociais - ocupou a discussão das teses selecionadas por ele ao pôr em questão a situação em que a cor do negro se tornou um problema.

0 problema não seria causado só pela segregação racial praticada pelo branco, mas pelo comportamento desajustado do negro ao sistema social igualitário. Embora o desajuste estivesse diminuindo, em decorrência das políticas de integração e da maior participação do negro nas oportunidades de trabalho, ainda acometeria a situação das relações de classe, atrasando a plena assimilação do negro pelo branco e a evolução das raças em classes, tão somente classes sociais.

Ao sistema social igualitário - visto pela utopia racionalista de Fernandes como perfeito, na medida em que a mobilidade das classes sociais resultaria no tratamento igual dos seres humanos (Garcia, 2002) - as discriminações baseadas na cor ou na raça das pessoas são disfuncionais. 0 comportamento do negro, atrasado, irracional diante da competição social, desajustado do ponto de vista da democracia moderna, também é disfuncional. Esta dupla disfunção, a do branco e a do negro, atrasa a modernização do sistema social e, se solucionada, não mais daria sentido à situação mais ampla e complexa do problema negro.

Esse dilema desapareceria do sistema social se as relações entre brancos e negros, com responsabilidade de ambos os lados, alcançassem a superação do obsoleto pensamento da existência de raças. Assim, o dilema da situação de desigualdade na sociedade norte-americana cessaria, ao passo que o Estado nacional desenvolveria melhores "mecanismos de desintegração social do regime de castas e processos alternativos de constituição de uma sociedade de classes, sem barreiras raciais e étnicas" (Fernandes, 1958: 105-106).

Para Fernandes, a modernização se fazia necessária nos Estados Unidos tanto quanto no Brasil. Bastide também afirmou que a sociedade norte-americana era composta por castas em evolução para classes, sem distinções raciais no futuro. 0 dilema da democracia no país do Norte, para esses sociólogos, tinha solução graças ao acúmulo de prescrições dos cientistas sociais colaboradores da Unesco. Da situação mais complexa em que as relações raciais eram o fator preponderante, passava-se agora para as técnicas de aprimoramento da democracia, numa investida internacional a favor da eliminação do racismo por meio da ascensão social do negro em regime igualitário com o branco.

Essas técnicas emergiram nos anos 1950, sendo apoiadas na tradição de estudos raciais, graças à agenda acadêmica norte-americana, desenvolvida em centros como Columbia, Chicago e Harvard. ${ }^{3}$ Mediante a rede transnacional de Bastide e Fernandes, na qual circulavam 
teses ao redor de impressos acadêmicos e jornalísticos, como International Social Science Bulletin, The Unesco Courier, Anhembi e O Estado de S. Paulo, as técnicas de aprimoramento do sistema democrático chegaram ao Brasil da mesma forma pela qual haviam ganhado uma síntese, um programa liberal-reformador de antirracismo. Ocorre que, em 1944, An American Dilemma foi lançado em Nova York.

\section{A PESQUISA NOS ESTADOS UNIDOS: EMERGÊNCIA DO DILEMA AMERICANO}

pesquisa que resultou em An American Dilemma não teve uma origem tão discrepante
da dos outros estudos raciais patrocinados por fundações norte-americanas na primeira metade do século XX, exceto algo particular no caminho seguido por Frederick Keppel, presidente da Carnegie Corporation em 1937, para atender aos anseios de sua fundação. Nos Estados Unidos, até a Segunda Guerra Mundial, era comum as grandes empresas privadas exercerem filantropia aos negros por meio de suas fundações.

Essas fundações, no Norte ou no Sul, miravam políticas de melhoria da educação da população negra. Mesmo realizada em escolas e faculdades próprias para negros, separadas dos brancos, a educação era o foco da ação das fundações, e isso estava em acordo com algumas associações negras, a exemplo da National Association for the Advancement of Colored People (NAAPC).

A educação dos negros camponeses, visando à formação de uma classe trabalhadora mais robusta, composta por operários e outras categorias mais bem qualificadas, inclusive de melhores trabalhadores rurais, refletia a ação das fundações em resposta aos constantes deslocamentos dos negros das fazendas do Sul para as cidades do Norte. A migração começou com força já no século XIX, após a abolição, mas aumentou consideravelmente no século XX, graças às transformações urbanas e tecnológicas decorrentes da Primeira Guerra Mundial.

Nos ardentes conflitos da Segunda Guerra, além da migração em massa para as grandes cidades, onde a maioria dos negros se aglomerava em guetos e outros bairros negros, até as tropas do Exército ianque, que combatiam os inimigos de guerra nas regiões europeias sob domínio nazista, foram divididas por critério de raça: negros para um lado, brancos para outro. A honra nacional por terem sido os vitoriosos da guerra se limitou aos soldados brancos. Aos negros, restou só a dádiva por terem sido convocados para lutar em nome de seu país (Higham, 1997).

Ao notar a insuficiência da filantropia há décadas realizada pelas fundações norte-americanas, diante do agravamento dos conflitos raciais particularmente no Sul, onde a segregação crescia em violência sistemática e se alastrava em regozijo do Jim Crow, Keppel admitiu que 
mudar as estratégias filantrópicas da Carnegie era necessário, e assim convocou uma seleção de intelectuais que pudessem orientar a mudança. Numa lista de 22 nomes, escolhera Gunnar Myrdal para o projeto. ${ }^{4}$

0 chefe da Carnegie sabia quão complexas ficavam as tensões raciais naqueles anos de 1930, mas não pretendia eliminar a segregação ao mudar a forma de apoio à população negra. Seu foco era fazer com que um intelectual apontasse mais efetivos sistemas de filantropia, de modo que o racismo nos Estados Unidos diminuísse. Eis que o acaso mostra sua face ao trazer Myrdal e seu conhecimento em engenharia social, uma área da ciência ao mesmo tempo anticomunista e reformista, muito próxima dos ideais político-sociais dos pioneiros da terceira via. ${ }^{5}$

Esperava-se certo avanço nas restrições que cercavam as discussões em torno do problema racial vivido nos Estados Unidos. Keppel dizia que tal discussão era tão carregada de emoção de ambos os lados, dos intelectuais negros e brancos, de Norte a Sul, que apenas um estrangeiro poderia chegar a uma interpretação suficientemente objetiva. Mas o acaso alterou seus planos:

Depois de muito procurar por um estrangeiro objetivo para fazer o trabalho, Keppel inadvertidamente escolheu um cientista social que não acreditava na objetividade da ciência social e que estava profundamente comprometido com a engenharia social. Myrdal, um forasteiro, não fazia parte do mundo das Ciências Sociais norte-americanas e seu compromisso com a ciência sem valores. Ele não precisava se submeter à revisão de seus pares. Foi a própria evasão de Myrdal da ortodoxia que tornou os cientistas sociais hesitantes a desenvolver recomendações de políticas para as relações raciais o que permitiria que o estudo tivesse impacto além do estrito mundo acadêmico. (Cohen, 2014: 11-12)

Feita a escolha, Myrdal teve liberdade para desenvolver o projeto da Carnegie. Não conheceu restrições ao estabelecer o escopo do projeto à sua maneira nem ao recrutar extenso grupo de assistentes para auxiliá-lo na pesquisa. Ampliara o projeto original e não recebera negativas de Keppel por causa disso. Numa tentativa de apaziguar a discórdia dos cientistas sociais norte-americanos, já que não aceitavam a escolha do estrangeiro para um projeto dessa envergadura, Myrdal selecionou um numeroso grupo de psicólogos sociais, sociólogos e antropólogos para prestarem assistência ao levantamento de fontes e dados pertinentes ao projeto.

Negros e brancos foram selecionados, a maioria das Universidades de Chicago, Columbia, Northwestern, Fisk e Howard, embora os assistentes mais importantes, por terem contribuído diretamente para o desenvolvimento da pesquisa, fossem pessoas da confiança de 
Myrdal, suecos como ele. É o caso de Richard Sterner, que, em nome da coordenação dos cientistas sociais participantes do projeto, viajara para os Estados Unidos ao lado de Myrdal a seu pedido (Southern, 1987).

Egresso da Escola Sociológica de Chicago, Arnold M. Rose ficou responsável pela coordenação da equipe junto com Sterner. Ambos os assistentes acompanharam de muito perto o desenrolar da pesquisa de campo feita por Myrdal em alguns estados sulistas logo que chegara ao país. A pesquisa de campo foi considerada decisiva, tanto quanto humanamente dramática, posto que a aproximação dos estrangeiros com a realidade nua e crua do racismo segregacionista do Sul os convenceu de que o problema para o qual a Carnegie buscava solução não resultava apenas do comportamento do negro. Era mais do que isso. Tratava-se de um dilema racial alimentado pelo branco. Seria, portanto, o racismo dos brancos, sua supremacia, o fator determinante na criação de um conflito, danoso e persistente, entre o credo norte-americano e a democracia dos e para os brancos.

Os objetivos do projeto foram ampliados depois dessa constatação, sem empecilhos ou outras dificuldades impostas por Keppel, pois a ele interessava observar o limite ao qual Myrdal chegaria depois de tomar conhecimento da situação de mal-estar civilizacional criada pela violência contra os negros do país. 0 dilema norte-americano, por conseguinte, passou a problema central da investigação em curso. Nela, Myrdal aplicou a mesma metodologia não neutra, capaz de reconhecer a ambivalência dos valores democráticos dos Estados Unidos, anteriormente desenvolvida em sua obra econômica - ponto de partida para sua interpretação da questão racial, entendida como problema negro. Tal compreensão foi suplementada com os dados dos assistentes acerca da ambivalência do credo norte-americano, isto é, o choque entre a ordenação do sistema democrático e as atitudes segregacionistas dos brancos contra os negros.

Arnold M. Rose recebeu a incumbência de terminar a redação de An American Dilemma quando Myrdal tivera que retornar à Suécia, em 1943, antes da conclusão do projeto. A pesquisa, graças ao trabalho complementar de Rose, tomou a forma final de An American Dilemma: The Negro Problem and Modern Democracy, livro escrito quase por inteiro pelo próprio Myrdal, cuja visão moral do dilema norte-americano era uma significativa diferença em relação ao que havia sido dito, quer em chave culturalista, quer em chave marxista, sobre as relações raciais naquele país.

Em suas mais de mil páginas, o livro enciclopédico trouxe um debate crítico com as teses de cientistas sociais como Robert E. Park, Franklin Frazier, Franz Boas, Ashley Montagu, entre outros. 0 sueco, ao rejeitar de novo o marxismo como modelo explicativo da desigualdade racial nos Estados Unidos - como fizera na obra acerca do desenvolvimento econômico 
DOIS PAÍSES, O MESMO DILEMA? REFLEXÕES SOBRE A DEMOCRACIA E O RACISMO NOS ESTADOS UNIDOS E NO BRASIL

mundial -, usou o princípio das causas acumulativas para explicar o distúrbio nos padrões urbanos e rurais de vida dos negros.

0 ponto fundamental consiste na tese de que um distúrbio no estágio inicial do equilíbrio sistêmico não estimula reações compensatórias nem tende a restaurá-lo. Ao contrário, o distúrbio produz mudanças que movem o sistema para longe de sua posição inicial. 0 padrão de vida dos brancos, muito superior ao dos negros, é visto como um distúrbio para o sistema igualitário norte-americano. 0 tratamento intensamente desigual dispensado ao grupo negro, na mesma sociedade do grupo branco, é visto como movimento que afastou, ao longo da história, o equilíbrio do sistema para muito longe da democracia, criando desse modo um dilema, que Myrdal começou a tese definindo:

0 problema negro é um problema no coração do americano. É aí que a tensão inter-racial tem seu foco. É aí que a luta decisiva continua. Tal é o ponto de vista central deste estudo. Nosso estudo aborda as relações raciais em chave econômica, social e política, e no fundo nosso problema é o dilema moral do americano: o conflito nos valores morais presentes em vários níveis de sua consciência e em seu cotidiano. 0 "dilema americano", a que referimo-nos no título deste estudo, é o atroz conflito entre, de um lado, os valores preservados no plano geral, que chamaremos de "credo americano", com o qual o americano pensa, fala e age sob a influência dos mais altos preceitos nacionais e cristãos, e, de outro lado, as apreciações em níveis específicos da vida individual e coletiva, nas quais interesses pessoais e locais; invejas econômicas, sociais e sexuais; noções de prestígio social e padrão de conformidade; preconceito de grupos contra pessoas em particular ou tipos de pessoas; e diferentes formas de desejos, impulsos e hábitos dominam sua perspectiva. (Myrdal, 1944: XLVII)

0 conflito interno no credo norte-americano, segundo Myrdal, corrompe o sistema democrático a tal ponto que chega a criar distúrbios quase irrecuperáveis para o sistema. A situação paradoxal do negro depois da abolição - livre, mas desigual - seria um reflexo da falta de equilíbrio na democracia. 0 autor resume a discussão ao argumentar que o padrão de vida dos negros se manteve, no pós-abolição, muito mais baixo do que o dos brancos: "De um lado, este padrão de vida é mantido baixo pela discriminação dos brancos, enquanto, de outro lado, a razão de os brancos discriminá-los [os negros] é parcialmente dependente do padrão de vida dos negros" (1944: 1066).

Problemas humanos, comportamentais ou estruturais, como pobreza, ignorância, superstição, favelas, deficiências de saúde, aparência de sujeira, conduta desordenada, mau cheiro e criminalidade, alimentavam a antipatia dos brancos em relação aos negros. 0 padrão de vida dos negros, ou sua situação social, foi a chave de Myrdal para a análise do dilema norte-americano. Para estudá-lo, o time de cientistas sociais assistentes entrara em ação, fornecendo dados e outras evidências sobre diversas variáveis de relações raciais. 
An American Dilemma analisou o padrão de vida dos negros em comparação com o do branco com variáveis relacionadas a emprego, salário, habitação, lazer, alimentação, saúde, educação, direitos civis, associativismo, ação coletiva etc. Trata-se de um estudo abrangente, menos histórico do que sociológico, com mescla de elementos behavioristas, funcionalistas e interacionistas, no qual prevaleceu a tese moral de que o negro era um problema do branco. Isso significa que o negro, à medida de seu desenvolvimento social, deveria ser normalmente assimilado pelo branco em seu estilo de vida, cultura e sistema democrático. 0 negro seria funcional para a democracia se o branco o integrasse à cidadania norte-americana, como acontecera com os outros grupos imigrantes.

A tese de Myrdal não demorou a encontrar boa acolhida entre os intelectuais dos Estados Unidos e de diversos outros países. 0 livro fizera estrondoso sucesso interna e externamente. Foram mais de 100 mil cópias vendidas no mundo inteiro entre 1944 e 1965, ano de sua segunda edição. 0 sucesso começou primeiro no meio intelectual de brancos e negros que apostavam na agenda antirracista como solução do problema negro, assim como importante fator de mudança social em direção à democracia moderna. Barber apontou a razão de o livro ter sido bem recebido nos primeiros tempos:

A chave foi o impacto sobre a consciência nacional baseado na convicção de Myrdal de que as ideias morais tinham força. Uma vez que uma mudança na direção positiva estivesse concluída, as causas acumulativas proveriam a dinâmica com mais aprimoramentos (2008: 74).

De fato, o economista-sociólogo demonstrou, de forma consistente, a tese das causas acumulativas, testando-a na análise empírica e explicando-a nas notas metodológicas apensadas ao livro, porque as causas acumulativas interferem no equilíbrio do sistema de variáveis socioeconômicas interdependentes e são a engrenagem da igualdade racial:

Entendemos que um movimento em qualquer uma das variáveis negras na direção dos níveis brancos tenderá a diminuir o preconceito do branco. Ao mesmo tempo, o preconceito do branco é responsável, direta ou indiretamente, pela mais efetiva manutenção dos níveis baixos relativos às variáveis negras. É também nossa hipótese que, no todo, o melhoramento de qualquer uma das variáveis negras tenderá a melhorar todas as outras variáveis negras e, assim, indiretamente assim como diretamente, resultará num acumulativo e reforçado efeito sobre o preconceito do branco. Um acréscimo no emprego tenderá a aumentar a renda; elevar os padrões de vida; e melhorar a saúde, a educação, o comportamento e a obediência civil, e vice-versa; uma melhor educação é capaz de aumentar as chances de empregos mais bem remunerados, e vice-versa; e assim em todo o percurso através de nosso completo sistema de variáveis. Cada uma das mudanças secundárias tem efeito sobre o preconceito do branco (MYRDAL, 1944: 1066-1067). 
DOIS PAÍSES, O MESMO DILEMA? REFLEXÕES SOBRE A DEMOCRACIA E O RACISMO NOS ESTADOS UNIDOS E NO BRASIL

Enquanto o impacto de An American Dilemma ultrapassava as fronteiras dos Estados Unidos, sua tese era debatida pelos intelectuais do país com muito interesse. Durante os anos 1940 e 1950, a recepção do livro acontecera sobretudo no mundo acadêmico. Cientistas sociais, economistas e historiadores norte-americanos, ligados principalmente à ideologia da terceira via, foram favoráveis à tese das causas acumulativas.

Os positivos comentários de Schlesinger, Frazier e Du Bois na imprensa nacional, enfatizando a urgente necessidade moral de dessegregação racial na nação, são um indício da recepção favorável de An American Dilemma. A importância do livro foi igualada à de obras penetrantes na vida norte-americana, em especial Democracy in America, de Alexis de Tocqueville, e The General Theory of Employment, Interest, and Money, de John Maynard Keynes (Southern, 1987).

Southern narrou o percurso da influência do livro quando grassava mundo afora. Membros da direita republicana atuante no Congresso, numa espécie de contra-ataque, costumavam negar a tese das causas acumulativas. Para isso, postularam o argumento de que o livro, de maneira mais ampla, não tinha sustentação. Se emocionava os norte-americanos com sua retórica sentimental sobre o credo democrático, desconhecia o modo de vida formado pelas longas e singulares relações entre patrões brancos e trabalhadores negros - os senhores e os escravos de outrora - no Deep \& Old South. A ala de direita alimentaria polêmicas sobre 0 livro desde o princípio, buscando obstaculizá-lo na esfera pública.

O impacto político, ao extrapolar os limites do mundo acadêmico, fez-se real a partir dos anos 1960. Na corte suprema, nas escolas primárias, no movimento pelos direitos civis e em muitas outras dimensões da esfera pública, o efeito da tese de Myrdal crescia na medida em que era usada para justificar atitudes visando a mudanças raciais irreversíveis na sociedade norte-americana.

Se a discriminação pelo branco passou a ser imoral e mesmo um pecado, prática incompatível com os ideais democráticos valorizados no pós-Segunda Guerra Mundial, a dessegregação racial e a integração do negro na sociedade de classes, por meio do mercado de trabalho, se tornaria o principal caminho defendido pelos adeptos da tese de Myrdal para a agenda de antirracismo. Chegavam, assim, a vislumbrar uma solução do problema negro acompanhada pelo desenvolvimento social e econômico do país (Southern, 1987).

Em "America Again at the Crossroads of the Negro Problem", desfecho do livro, Myrdal expôs a circunstância histórica oportuna para o desenvolvimento internacional do antirracismo pela liderança geopolítica dos Estados Unidos no contexto do pós-Segunda Guerra Mundial. Também presente em diferentes passagens da obra estava a tese explicativa da 
desigualdade na sociedade de classes, ou seja, o sistema de variáveis interdependentes. Essa tese, na passagem dos anos 1950 para os 1960, foi tida por muitos como capaz de prever consequências do problema negro para o sistema social igualitário, assim como tendências decisivas nas ações de eliminação do racismo.

Os intelectuais de esquerda não estariam mais desalentados em sua atuação contra o racismo, tampouco estariam ilhadas as organizações negras em sua luta pela ascensão social. Ambos os setores civis receberam apoio do Estado, da Justiça e dos governos eleitos. As políticas de ação afirmativa implementadas a favor da dessegregação racial foram apoiadas pelos líderes do movimento nacional pelos direitos civis, sendo Martin Luther King Jr. o grande guia do protesto não violento.

As mudanças raciais em curso nos Estados Unidos contaram com a defesa da Organização das Nações Unidas (ONU) e da Unesco, instituições das quais o casal Gunnar e Alva Myrdal era administrador e líder intelectual. A tese de An American Dilemma e o programa de antirracismo nele desenvolvido tiveram impacto na construção dessas mudanças pelos sujeitos inconformados, de uma forma ou de outra, com as agruras e os sofrimentos gerados pelo racismo nos Estados Unidos. ${ }^{6}$

Ao olharmos para o mundo acadêmico do Brasil, observamos que as políticas da Unesco alargaram o elo dos cientistas sociais da Universidade de São Paulo (USP) com o pensamento de Myrdal, constituído por frequentes diálogos com a tese central de seu An American Dilemma. Um desafio estava colocado a esses cientistas sociais: era possível comparar as duas sociedades diferentemente do pensamento de Gilberto Freyre?

\section{A EMERGÊNCIA DO DILEMA BRASILEIRO: DIÁLOGO SOCIOLÓGICO INTERNACIONAL}

\footnotetext{
omo sociedades de castas são formadas? Como ocorre a transição desse sistema social para o de classes? Como raças entram em evolução para classes sociais e livram as sociedades dos preconceitos antidemocráticos? Qual a função do negro e do branco nesse processo social? O que, afinal, significam raça, casta, estamento e classe? Enfim, como se operam tais conceitos teóricos na análise da discriminação racial no Brasil? Lado a lado com a tradição formada principalmente pelos estudos interacionistas e culturalistas de Chicago e Columbia, An American Dilemma trazia respostas a essas perguntas, dado seu volume enciclopédico de conceitos teóricos, métodos e técnicas em ciências sociais. ${ }^{7}$
} 
Em São Paulo, a princípio, os cientistas sociais profissionais e em formação, ligados à Escola Livre de Sociologia e Política (Elsp) e à Faculdade de Filosofia da USP, usaram o livro em suas pesquisas sobre as relações raciais brasileiras desde o desenvolvimento do Projeto Unesco. ${ }^{8}$ Entender An American Dilemma lhes parecia essencial em termos do manejo de conceitos teóricos universais e explicativos de processos histórico-sociais não restritos aos Estados Unidos.

Assim aconteceu a recepção do livro no Brasil. Era uma leitura obrigatória, caso o pesquisador tivesse expectativa de desenvolver estudos de relações raciais sérios. Com a incorporação do pensamento de Myrdal, tornou-se possível fazer diagnósticos acerca do tratamento historicamente dispensado ao negro resultante na desigualdade brasileira.

Embora os principais depoimentos de Fernandes (1977 e 1978a) em torno de sua formação intelectual sejam bastante discretos ao nos revelar as inspirações teóricas que o animaram, nossa pesquisa, mais acurada, encontrou um comentário em que ele reconhece a importância decisiva de Myrdal para as ciências sociais. Em sua visão, o economista-sociólogo sueco era um inovador homem de ciência:

Um homem que representa a tradição europeia, esse Myrdal, ele escreve um livro todo sobre o elemento político na economia [referindo-se ao The Political Element in the Development of Economic Theory, de 1953]. Um professor americano poderia escrever uma biblioteca toda, uma enciclopédia para provar que não deve existir elemento político na ciência. Esse é um contraste vigoroso. É por isso que o livro de Myrdal, An American Dilemma, aqueles apêndices tiveram uma importância tão grande nos Estados Unidos, porque levaram a uma fermentação nova (1978b: 26).

No momento em que o sucesso mundial de An American Dilemma era evidente, a fermentação de teses inovadoras não acontecia apenas no mundo acadêmico dos Estados Unidos. Em São Paulo, o ambiente intelectual era adequado à recepção absortiva do livro, graças à crescente institucionalização das ciências sociais na Elsp e na Faculdade de Filosofia desde os anos 1930. 0 modelo de ensino e pesquisa da Escola Paulista praticado nesse momento estava inspirado no de Chicago, e os cientistas sociais de Chicago foram os que mais contribuíram para a pesquisa de An American Dilemma, a despeito dos demais centros norte-americanos. Assim, podemos ver que a formação intelectual dos pesquisadores paulistas permitiu a absorção da tese central de An American Dilemma, bem como de seu programa antirracista proposto em bases liberal-reformadoras.

Os usos de An American Dilemma pelos paulistas, nos anos 1950, diferiram dos da década anterior, apresentando tendência de crescimento. Esses intelectuais ainda eram os 
principais apoiadores do livro no Brasil, mas seus usos pouco a pouco deixaram de ser ocultos e começaram a ser mais pronunciados. Parece que falar sobre o racismo na década anterior era algo mais arriscado e menos incentivado do que na década seguinte, quando os cientistas sociais de São Paulo se sentiram confiantes para lançar uma antítese à interpretação da sociedade brasileira desenvolvida em Casa-grande \& senzala. ${ }^{9}$

Quando, em 1953, entravam em fase de conclusão os inquéritos sobre valores, comportamentos e atitudes característicos das relações raciais no espaço paulista, Paulo Duarte (1947) publicou uma nota introdutória a seus resultados em Anhembi. Longe do que afirmara seis anos antes, em $O$ Estado de $S$. Paulo, a respeito da cordialidade e da ausência de racismo no Brasil, dessa vez os novos estudos do negro assumiram um caráter urgente.

O projeto da Unesco tinha importância à medida que esclareceria um problema cada dia mais grave para a democracia brasileira: o tema negro. Essa investigação, todavia, não tinha abrangência apenas nacional. Sua universalidade decorre, para ele, da oportunidade de compreender inconsistências, restrições e males que a temática negra, sub-reptícia e ardilosamente, causa ao sistema democrático. Conhecer as causas dessa questão era, assim, fundamental:

Foi assim que Unesco e Anhembi se encontraram unidas na realização de um mesmo trabalho de alta significação universal, como seja uma análise objetiva mas feita em profundidade sobre a vida da população negra do Brasil, país universalmente considerado como aquele que melhor solução estava dando ao problema, entre todos os países brancos possuidores de importante parcela de população de cor. (Duarte, 1953: 433)

A urgência do projeto da Unesco, elevada a um consenso entre os intelectuais colaboradores de Anhembi, era tamanha que em três anos os inquéritos foram concluídos. ${ }^{10} \mathrm{~A}$ metodologia da pesquisa dos paulistas, contando com um time de psicólogos sociais e sociólogos que aplicaram testes e questionários entre pessoas negras e brancas, entrou em harmonia com os métodos da Escola de Chicago, como a observação participante, a história de vida, as entrevistas individuais e coletivas e os fóruns de debate com ativistas do movimento negro local. Essa foi a mesma metodologia estabelecida por Myrdal para seus assistentes na pesquisa de An American Dilemma.

Ao modo dos cientistas sociais ianques, os paulistas analisaram as principais variáveis constitutivas do padrão de vida dos negros. A primeira conclusão a que chegaram é parecida com a de Myrdal: há um círculo vicioso em São Paulo, resultante da discriminação racial, que empurra o padrão de vida dos negros para baixo e não os deixa ascender livremente na escala social (Bastide e Fernandes, 1959). 
A ascensão social do negro e do mulato encontra barreiras raciais desde o século XIX, na medida em que os indivíduos com tais cores tentam crescer na competição social, esforçando-se para vencê-la em busca das melhores oportunidades no mercado. Lembremos que o tema das pesquisas feitas em São Paulo reside na situação do negro na ordem competitiva, fundante do sistema social igualitário. Isso significa que o interesse dos cientistas sociais, ao contrário das sobrevivências africanas na cultura negra contemporânea, se concentrava na inserção do negro e do mulato no mercado de trabalho. Tal questão era, na verdade, uma diretriz endossada pela Unesco e observada por Bastide, Fernandes e seus assistentes, igualmente interessados no direcionamento da pesquisa dado pela organização internacional.

Se o preto e o pardo sofrem discriminação racial nas áreas modernas e industriais do país, a ordem competitiva apresenta inconsistências de natureza estrutural. 0 problema negro seria de estrutura social e merecia solução urgente. É a origem do problema a mesma dos Estados Unidos? Ficou clara, nas Relações raciais entre negros e brancos em São Paulo, a tese nativa segundo a qual, no Brasil, ao contrário dos Estados Unidos, há preconceito de marca, e não de origem. Desse modo, o branco racista discrimina, antes de tudo, a cor ou o fenótipo das pessoas pretas e pardas, assim como tudo o que essas cores representam simbolicamente, para ele, em termos negativos.

Nos Estados Unidos, numa comparação que exprime graus de intensidade dos racismos, a discriminação é, sobretudo, de origem, atitude preconceituosa mais explícita e violenta por causa de sua tendência à exclusão de todas as pessoas com origens étnicas e nacionais diferentes da supremacia branca norte-americana (Nogueira, 1955).

O primeiro ciclo brasileiro de pesquisas raciais da Unesco chegara ao fim na virada da década de 1950 para a de 1960, mas as obras dele resultantes ainda eram publicadas consecutivamente. Em 1957, antes do definitivo encerramento do ciclo, Bastide chamou a atenção para o dilema brasileiro no International Social Science Bulletin. Trata-se de uma das primeiras vezes em que o racismo dos Estados Unidos foi comparado ao do Brasil de forma invertida, em Brazil: An Interpretation, de Gilberto Freyre.

Myrdal falou do "dilema americano". Talvez o conjunto de fatos e interpretações discutidos neste artigo possam ser resumidos ao dizermos que há também um "dilema brasileiro". 0 distúrbio da estrutura social e o desenvolvimento das ideias democráticas estão tendendo a substituir o velho paternalismo pela luta não mais por igualdade formal, mas agora econômica e racial. Esta luta enseja consciência racial entre as pessoas de cor e discriminação entre os brancos [...] No Brasil industrial, este dilema é revelado, neste momento, pela forma que a discriminação assume [...] A grandeza do Brasil consistirá em sair de seu dilema passando do paternalismo ao igualitarismo sem perder, na passagem, as qualidades de amor, de tolerância, de respeito mútuo, que caracterizam seus filhos (1957: 512). 
Bastide afirmou que, no Brasil, se vive um dilema similar ao norte-americano. Em termos de racismo, é parecido, mas não idêntico, o que cria um drama humano, mal-estar e violência menos intensos do que os existentes nos Estados Unidos. A diferença elementar entre os racismos, para ele, se refere à escala de violência contra os negros. Enquanto nos Estados Unidos os brancos excluíam os negros da democracia pelas armas do preconceito, da discriminação e da segregação legalizadas, no Brasil os negros não eram violentados com leis de segregação racial, mas havia, de fato, sub-reptício racismo à brasileira. 0 termo não foi dito nesse momento por Bastide, com essas palavras, embora sua reflexão já exprimisse o mesmo sentido.

A forma assumida pela discriminação do negro no Brasil, então se entendia, é a do racismo à brasileira, um modo enganosa de manter o negro em seu lugar, com pouco status e baixo padrão de vida. Antes mesmo do International Social Science Bulletin, essa foi a tese desenvolvida por Bastide e Florestan nos artigos de Anhembi, logo depois reunidos nas Relações raciais entre negros e brancos em São Paulo.

As atitudes e os comportamentos de discriminação no Brasil atravessariam uma escala entre 0 e $X$, na qual $X$ significa abertura indefinida para a violência contra o negro, cada vez mais exacerbada, próxima do racismo norte-americano. Mas ainda prevaleceria, mesmo nas maiores metrópoles, uma forma enganosa de discriminação racial, diferente da dos Estados Unidos:

A um negro é negado um cargo não porque ele é negro - ele é informado que a vaga infelizmente acabou de ser preenchida. A ele não é negada uma promoção na carreira profissional - ele não é aprovado no exame médico. Esta solução, que não engana ninguém, obviamente não pode durar (Bastide, 1957: 512).

O racismo velado não pode durar, senão o sistema democrático no Brasil não alcança o equilíbrio necessário para acelerar a modernização. Não pode durar porque o racismo entrou num círculo vicioso que atrasa a modernização. A transição completa para o sistema social igualitário, preservando as características positivas da cultura brasileira, só estaria verdadeiramente completa com a solução do dilema brasileiro e nosso problema negro. As raças ainda fazem sentido nas relações sociais, ao passo que, sociologicamente, o sistema social igualitário é incompatível com o pensamento racial - daí o fato de nosso dilema ter tido destaque no ciclo de pesquisas da Unesco, sendo constante motivo de preocupação para cientistas sociais e diretores da organização internacional.

Em 1964, Fernandes aprofundou o estudo da desigualdade brasileira com sua tese para professor titular da USP: A integração do negro na sociedade de classes. Conquanto nativa, a interpretação da questão racial continuou se valendo do argumento das causas acumulativas de Myrdal: 
DOIS PAÍSES, O MESMO DILEMA? REFLEXÕES SOBRE A DEMOCRACIA E O RACISMO NOS ESTADOS UNIDOS E NO BRASIL

Como ex-agentes do trabalho escravo e do tipo de trabalho manual livre que se praticava na sociedade de castas, o negro e o mulato ingressaram nesse processo [o de constituição da ordem social competitiva] com desvantagens insuperáveis. As consequências sociopáticas da desorganização social imperante no "meio negro" ou da integração deficiente à vida urbana concorreram para agravar o peso destrutivo dessas desvantagens, aniquilando ou corroendo até as disposições individuais mais sólidas e honestas de projetar o "homem de cor" no aproveitamento das oportunidades em questão. Desse ângulo, percebe-se com facilidade como a degradação pela escravidão, a anomia social, a pauperização e a integração deficiente combinam-se entre si para engendrar um padrão de isolamento econômico e sociocultural do negro e do mulato que é aberrante em uma sociedade competitiva, aberta e democrática. (1965: 192)

A favelização do negro é aberrante, para ele, porque reproduz incessantemente o dilema brasileiro, emergido ao mesmo tempo que nascera a sociedade de classes:

Delineia-se claramente, assim, o dilema racial brasileiro. Visto em termos de uma das comunidades industriais em que o regime de classes sociais se desenvolveu de modo mais intenso e homogêneo no Brasil, ele se caracteriza pela forma fragmentária, unilateral e incompleta com que esse regime consegue abranger, coordenar e regulamentar as relações raciais. Essas não são totalmente absorvidas e neutralizadas, desaparecendo atrás das relações de classes. Mas se sobrepõe a elas, mesmo onde e quando as contrariam, como se o sistema de ajustamentos e de controles sociais da sociedade de classes não contivesse recursos para absorvê-las e regulá-las socialmente (Idem: 391).

Vendo a reprodução incessante do dilema brasileiro, que não permite que as relações de raça se tornem relações de classe numa sociedade de classes democrática, resta a Fernandes lançar, em A integração do negro na sociedade de classes, sua conclusão final, análoga à de An American Dilemma, relativa aos Estados Unidos:

Essa explicação permite situar o problema do negro de uma perspectiva realmente sociológica. Ele não constitui um "problema social" apenas porque evidencia contradições insanáveis no comportamento racial dos "brancos", porque traduz a persistência indefinida de padrões iníquos de concentração racial da renda, do prestígio social e do poder ou porque, enfim, atesta que uma parcela considerável da "população de cor" sofre prejuízos materiais e morais incompatíveis com os fundamentos legais da própria ordem social estabelecida. Esses sintomas conduzem à superfície o mal crônico, que é mais grave e pernicioso. Trata-se das condições mínimas de diferenciação e de integração normais de um sistema social. (1965: 392)

Perde o sistema social igualitário, perdem os cidadãos, perde a nação. As novas teses brasileiras de relações raciais logo viajaram de volta para os Estados Unidos, graças a sua rápida e eficiente difusão no mundo acadêmico daquele país. Em 1953, Richard Morse, então professor de história das américas em Columbia, publicou um artigo no The Journal of Negro 
History (1953). Fernandes foi aqui considerado um inovador cientista social que, desafiando o imponente pensamento de Freyre, desenvolvia uma nova interpretação do Brasil: o dilema brasileiro. Não continua o Brasil a ser pensado por cientistas sociais e historiadores de ambos os países como um dilema nacional até nossos dias? Acredito que a história da sociologia ainda tenha muito a dizer sobre essa questão.

\section{NOTAS}

1 Anhembi era identificada por seu criador, Paulo Duarte, como uma revista de cultura. Foi criada em São Paulo, em 1950, em alinhamento ao ideário liberal dos pioneiros da USP, centrado fundamentalmente no papel da ciência como orientação dos rumos da sociedade. Em seu apogeu, graças à tão profícua parceria estabelecida com a Unesco, o periódico dera uma contribuição significativa para o debate contemporâneo sobre relações raciais relativo não só ao Brasil, mas de forma universal. Artigos dessa natureza, produzidos, por exemplo, pelos sociólogos Oracy Nogueira, Roger Bastide, Florestan Fernandes, Octavio lanni e Fernando Henrique Cardoso, eram comuns em suas páginas. Entretanto, a revista teve de encerrar as atividades em 1962, em virtude de uma grave crise financeira (Hayashi, 2010).

20 livro Relações raciais entre negros e brancos em São Paulo, organizado por Roger Bastide e Florestan Fernandes, é só um exemplo das várias pesquisas raciais financiadas pela Unesco no Brasil entre os anos 1950 e 1960. Foi publicado pelo convênio Anhembi/Unesco, em 1955, e contou com monografias, além das dos organizadores, de Oracy Nogueira, Virgínia Bicudo e Aniela Ginsberg. Em 1959, na segunda edição da obra, inscrita na Coleção Brasiliana da Companhia Editora Nacional, foram excluídas as monografias dos outros pesquisadores, com exceção de Bastide e Fernandes, e seu título foi encurtado para Brancos e negros em São Paulo.

3 Representativa dessa tradição intelectual é a coletânea Race Relations and the Race Problem, organizada por Thompson (1939), em que um conjunto de cientistas sociais, sob a liderança de Robert Park, abordou 0 racismo do ponto de vista interacionista. A pergunta-chave do livro era: como a compreensão do conflito racial pode auxiliar a integração da sociedade norte-americana?

4 Economista e sociólogo sueco, Myrdal já era um social-democrata fortemente anticomunista e reformista em meados dos anos 1930. A primeira edição de seu livro The Political Element in the Development of Economic Theory apareceu nessa época, exprimindo um economista crítico das leis naturais de Adam Smith e do utilitarismo de John Stuart Mill. Foi discípulo do também sueco Knut Wicksell, cujas lições em economia, em síntese, giram em torno da importância da teoria monetária para o equilíbrio das naç̧ões. Myrdal buscou expor, ao longo de sua trajetória, as falácias dos teóricos clássicos e tornar possível a introdução de premissas de valor, como moralidade, crenças e costumes, na análise social e econômica. Ganhou o Nobel de Economia pelo conjunto da obra em 1974 (Barber, 2008).

5 Arthur M. Schlesinger Jr., Eleanor Roosevelt, Walter Reuther e outros precursores do Americans for Democratic Action (ADA), embrião do que mais tarde se tornaria a Unesco, além de intelectuais como Edward Franklin Frazier, Gunnar Myrdal, Hanna Arendt, Ashley Montagu e Margaret Mead, foram importantes agentes do movimento internacional pelos direitos humanos. Apoiado pelo presidente Harry Truman, o movimento foi configurado em torno da ideia de third force, uma estratégia política não alinhada nem à esquerda nem à direita, mas ao centro vital, tendo a defesa do desenvolvimento econômico como engendrador da liberdade. A agen- 
DOIS PAÍSES, O MESMO DILEMA? REFLEXÕES SOBRE A DEMOCRACIA E O RACISMO NOS ESTADOS UNIDOS E NO BRASIL

da dos direitos humanos, por enfocar setores marginalizados da sociedade, pressupunha, desde o começo, essa concepção político-ideológica. Ela era o caminho, diziam seus inventores, para as democracias ocidentais evitarem a infiltração da ideologia comunista, especialmente nos países subdesenvolvidos (Cancelli, 2012).

$6 \mathrm{~A}$ inconformidade à falta de democracia desconheceu consenso tão absoluto assim. Imediatamente, alguns intelectuais se posicionaram contra a tese de Myrdal e rejeitaram seu programa de antirracismo liberal-reformador. Foi o caso de Ralph Ellison e Carter Woodson, dois ativistas negros, e de Herbert Aptheker, membro do Partido Comunista dos Estados Unidos. As críticas desses intelectuais tiveram em comum a rejeição do reformismo presente no livro. Haveria um compromisso político de Myrdal com a modernização da sociedade americana, o qual se sobreporia à interpretação mais isenta da questão negra. A visão liberal do autor resultaria de seu compromisso político-ideológico com os ideais de modernidade burgueses. Para ambos os ativistas negros, o reformismo implicava a nociva negação da originalidade da cultura afro-americana, ao passo que, para o comunista, Myrdal era um representante da classe dominante, cujas reformas liberais atenderiam somente às prementes necessidades de mudança da ordem capitalista, tornando-a mais tolerante com diferenças étnico-raciais (Ellison, 2003).

7 Estudos bem informados sobre a história das ciências sociais no Brasil e no exterior são encontrados em Stocking, 1982; Oliveira, 1987; Miceli, 1989 e 1995; Cuche, 2008; Maia e Pereira, 2009; Brasil Júnior, 2013; Meucci, 2015; Maio e Lopes, 2017.

8 No que toca à fração paulista, já na segunda nota de rodapé do projeto de pesquisa coletivo, escrito por Florestan e revisado por Bastide, nota-se a onipresença de An American Dilemma e das obras clássicas de Chicago, recomendadas como referência obrigatória no campo intelectual e usadas como fundamentação teórica da pesquisa a ser desenvolvida (Bastide e Fernandes, 1959: 323).

9 Em 1948, em "A análise sociológica das classes sociais", artigo aparecido pela primeira vez em Sociologia - Revista didática e científica, editada pela Elsp, Florestan relativizou a significação do conceito de classes sociais. Nessa relativização, porém, afirmou que a conceituação de Myrdal, desenvolvida nos apêndices de An American Dilemma, era a mais próxima da realidade social, já que não definia classe só como condição material, mas, paralelamente, como valores e crenças constitutivas das identidades (Fernandes, 1948: 112).

100 problema negro recebeu tanta atenção no Brasil que Anhembi com frequência abordava 0 assunto. Avanços científicos, com pretensão de universalidade, em torno do pensar e do equacionar a questão racial em múltiplos países, logrados por cientistas sociais franceses, ingleses, mexicanos etc., foram trazidos à tona pela revista em busca da instrução antirracista de seu público leitor. Evidência disso é o artigo "0 racismo e a ciência" (1954), no qual a crítica à discriminação racial identificada no Brasil foi feita à luz das conclusões de Arnold M. Rose, em The Origins of Prejudice, e Michel Leiris, em Race et Civilisation. Esses sociólogos participaram de um projeto mais amplo da Unesco, intitulado The Race Question in Modern Science, responsável pelas novas dimensões do conceito de raça. Para uma análise transnacional da atuação da Unesco no campo das relações raciais, ver Cancelli, Mesquita e Chaves, 2019. 


\section{REFERÊNCIAS BIBLIOGRÁFICAS}

BARBER, William J. Gunnar Myrdal: An Intellectual Biography. Nova York: Palgrave MacMillan, 2008.

BASTIDE, Roger; FERNANDES, Florestan. Brancos e negros em São Paulo. 2. ed. rev. e ampl. São Paulo: Nacional, 1959.

BASTIDE, Roger. Foreword. International Social Science Bulletin, Unesco, v. IX, n. 4, p. 423-427, 1957.

Race Relations in Brazil. International Social Science Bulletin, Unesco, v. IX, n. 4, p. 495-512, 1957.

BRASIL JÚNIOR, Antonio da Silveira. Passagens para a teoria sociológica: Florestan Fernandes e Gino Germani. São Paulo: Hucitec, 2013.

CANCELLI, Elizabeth. O Brasil e os outros: o poder das ideias. Porto Alegre: EdiPUCRS, 2012.

; MESQUITA, Gustavo; CHAVES, Wanderson. Guerra Fria e Brasil: para a agenda de integração do negro na sociedade de classes. São Paulo: Alameda, 2020 [no prelo].

COHEN, Shari. The Lasting Legacy of An American Dilemma. Nova York: Carnegie Corporation, 2014.

CUCHE, Denys. Roger Bastide, el "fait individuel" et l'École de Chicago. Cahier Internationaux de Socioligie, Paris, v. 1, n. 124, p. 41-59, 2008.

DUARTE, Paulo. Negros do Brasil. O Estado de S. Paulo, 16 de abril de 1947.

Relações raciais entre negros e brancos em São Paulo. Anhembi, São Paulo, v. 9, n. 25, 1953.

ELLISON, Ralph. An American Dilemma: A Review. In: ELLISON, Ralph. The Collected Essays of Ralph Ellison. Nova York: Modern Library, 2003 [1944].

FERNANDES, Florestan. A análise sociológica das classes sociais. Sociologia, São Paulo, v. 10, n. 2/3, p. 91 $113,1948$.

FERNANDES, Florestan. A condição de sociólogo. São Paulo: Hucitec, 1978a.

. A integração do negro na sociedade de classes. São Paulo: Edusp/Dominus, 1965.

A sociologia no Brasil: contribuição para o estudo de sua formação e desenvolvimento. Petrópolis: Vozes, 1977.

. Entrevista concedida a Mariza Peirano no CPDOC. Rio de Janeiro: CPDOC/FGV, $1978 \mathrm{~b}$.

. O negro nos Estados Unidos. Anhembi, São Paulo, v. 23, ano 8, n. 94, 1958, p. 105.

FREYRE, Gilberto. Brazil: An Interpretation. Nova York: Alfred Knopf, 1945.

. Casa-grande \& senzala. 50. ed. São Paulo: Global, 2005 [1933].

GARCIA, Sylvia Gemignani. Destino ímpar: sobre a formação de Florestan Fernandes. São Paulo: Editora 34, 2002.

GUIMARÃES, Antonio Sérgio Alfredo. Racismo e antirracismo no Brasil. 3. ed. São Paulo: Editora 34, 2009.

HAYASHI, Marli Guimarães. Paulo Duarte, um quixote brasileiro. São Paulo: Hucitec, 2010. 
DOIS PAÍSES, O MESMO DILEMA? REFLEXÕES SOBRE A DEMOCRACIA E O RACISMO NOS ESTADOS UNIDOS E NO BRASIL

HIGHAM, John (ed.) Civil Rights and Social Wrongs: Black-White Relations Since World War II. Philadelphia: The Pennsylvania State University Press, 1997.

MAIA, João Marcelo Ehlert; PEREIRA, Luís Fernando Almeida. Pensando com a sociologia. Rio de Janeiro: FGV, 2009.

MAIO, Marcos Chor. A história do Projeto Unesco: estudos raciais e ciências sociais no Brasil. Tese (Doutorado em Ciência Política) - Instituto Universitário de Pesquisas do Rio de Janeiro/Universidade Cândido Mendes, Rio de Janeiro, 1997.

; LOPES, Thiago da Costa. Entre Chicago e Salvador: Donald Pierson e o estudo das relações raciais. Estudos Históricos, Rio de Janeiro, v. 30, n. 60, p. 115-139, 2017.

MEUCCI, Simone. Artesania da Sociologia no Brasil: contribuições e interpretações de Gilberto Freyre. Curitiba: Appris, 2015.

MICELI, Sérgio (org.). História das ciências sociais no Brasil (v. 1). São Paulo: Vértice, 1989.

História das ciências sociais no Brasil (v. 2). São Paulo: Sumaré, 1995.

MORSE, Richard. The Negro in São Paulo, Brazil. The Journal of Negro History, Chicago, v. 38, n. 3, p. 290-303, 1953.

MYRDAL, Gunnar. With the assistance of Richard Sterner and Arnold Rose. An American Dilemma: The Negro Problem and Modern Democracy. Nova York: Harper \& Brothers, 1944.

NOGUEIRA, Oracy. Preconceito racial de marca e preconceito racial de origem: sugestão de um quadro de referência para a interpretação do material sobre relações raciais no Brasil. Anhembi, São Paulo, v. 18, ano 5 , n. 53, p. 279-299, 1955.

OLIVEIRA, Lúcia Lippi. Donald Pierson e a sociologia no Brasil. Revista Brasileira de Informação Bibliográfica em Ciências Sociais, São Paulo, n. 23, p. 35-48, 1987.

O RACISMO e a ciência. Anhembi, São Paulo, v. 6, ano 4, n. 16, 1954.

SOUTHERN, David W. Gunnar Myrdal and Black-White Relations: The Use and Abuse of An American Dilemma, 1944-1969. Baton Rouge: Louisiana State University Press, 1987.

STOCKING, George W. Race, Culture and Evolution: Essays in the History of Anthropology. Chicago: University of Chicago Press, 1982.

THOMPSON, Edgar T. (ed.) Race Relations and the Race Problem: A Definition and An Analysis. Durham: Duke University Press, 1939. 